\title{
SIN MEDIOS DE NEGOCIACIÓN LAS INSURRECCIONES DE INDIOS EN SONORA, 1855-1859
}

WITHOUT MEANS OF NEGOTIATION

THE INDIAN INSURRECTIONS IN SONORA, 1855-1859

\author{
Edna Lucía GARCía Rivera \\ Universidad de Sonora \\ lucia_ah@hotmail.com
}

Resumen

El presente trabajo explica las insurrecciones de indios de 1855 a 1859, a través del marco teórico de la subalternidad centrando la atención en los intentos previos de negociación, intereses particulares que remitían a intereses grupales, conciencia reflexiva al interior de los grupos, así como un proceso de subalternización por parte del Estado a través de legislaciones especiales. Para lo anterior se retoman las propuestas de Ranahit Guha, Robert Fletcher y Salomón Tarquini. Mediante la correspondencia de tenientes indígenas de los pueblos ópatas y de reportes de la sociedad mestiza, se encuentra que ciertos grupos ópatas y yaquis utilizaron la insurrección como una forma de participar políticamente y recuperar los cargos militares indígenas de capitanes generales. A partir de lo anterior, existió una conciencia al interior, misma que no era producto de insurrecciones espontáneas, sino de intentos previos de negociación e insurrección cuando no existía el pacto. Un ejemplo de lo anterior fue la contraposición a las políticas provenientes de Ignacio Pesqueira por parte de las gavillas de indios, que ejecutarán su acción buscando destituirlo del gobierno en apoyo a Manuel María Gándara.

Palabras clave: subalternidad, subalternización, insurrecciones, sublevaciones, gavillas.

\begin{abstract}
The present work explains the origin of the insurrections of Indians in the middle of the 19th century as a subaltern movement characterized by uprisings with previous attempts of negotiation. Also, particular interests that referred to group interests, reflective awareness within the sheaves, as well as a process of subalternization by the State through special legislation. Therefore, the theoretical framework of subalternity proposed by Ranahit Guha, Robert Fletcher and Solomon Tarquini is taken up again. From the above, it is found that through the correspondence of indigenous lieutenants of the Opata peoples, as well as reports by the Mestizo society of thefts and disturbances of order in the Yaqui territory, which in Opata and Yaqui groups, used the insurrection through sheaves, as ways to participate politically and recover the indigenous military positions of general captains.
\end{abstract}

Keywords: subalternity, subalternization, insurrections, uprisings, sheaves.

Información del artículo

Recibido: 11 de diciembre de 2018.

Aceptado: 14 de mayo de 2019.

DOI: 10.22201/iih.24485004e.2019.57.68017 
Tradicionalmente la historiografía que aborda las sublevaciones indígenas en los conflictos políticos sonorenses decimonónicos se centra en destacar las acciones políticas de los líderes de la élite de cada uno de los bandos conservadores, liberales, imperialistas y republicanos. Tangencialmente se ha mencionado la participación de cabecillas ópatas y yaquis sin explicar a sus seguidores, ni los motivos e intereses que propiciaron su levantamiento; por lo general se generaliza a yaquis, mayos y ópatas como brazo armado de un miembro de la élite y de sus propios intereses políticos.

A partir de esta mirada, autores como Evelyn $\mathrm{Hu}$ DeHart, en su libro Yaqui. Resistance and Survival, ofrece un análisis de las tradiciones y los valores que han impulsado a los yaquis a su actuar, enmarcándolo en el origen histórico de la "lucha yaqui para sobrevivir durante el xIx y xx"; ${ }^{1}$ para lo anterior, explica la actuación de cabecillas indígenas, tanto ópatas como yaquis, centrando su mirada en el conflicto de Juan Banderas; rebelión que perduró de 1825 a 1832, cuyas referencias derivaban de la lucha por evitar el despojo de sus tierras y rechazar la presencia de la población no indígena en dichas zonas. Juan Banderas buscaba establecer una confederación indígena que incluyera yaquis, mayos, ópatas, pimas y eudeves para enfrentar a los españoles "ladrones de tierras". La rebelión se propagó hasta territorio ópata en donde participaron los hermanos Dolores y Virgen Gutiérrez como cabecillas del movimiento. ${ }^{2}$

Dentro de este tenor, los textos de Hernández Silva, Insurgencia y autonomía, ${ }^{3}$ y Cynthia Radding, Entre el desierto y la sierra. Las naciones o'odham y teguima de Sonora, analizan los enfrentamientos políticos que tuvieron los yaquis durante el siglo XIX, y las formas de resistir ante los embates del liberalismo. Cynthia Radding realiza un recorrido de tres siglos: desde la conquista española hasta los primeros años de la república -1530 a 1840 - en pos de conocer a la comunidad indígena ${ }^{4}$ de la zona serrana, su

${ }^{1}$ Evelyn Hu DeHart, Yaqui Resistance and Survival: The Struggle for Land and Autonomy, 1821-1910, Madison (Wisconsin), The University of Wisconsin Press, 1984.

${ }^{2}$ Ignacio Almada Bay, Breve historia de Sonora, México, Fondo de Cultura Económica/ El Colegio de México, 2000, p. 120.

${ }^{3}$ Héctor Cuauhtémoc Hernández Silva, Insurgencia y autonomía. Historia de los pueblos yaquis: 1821-1910, México, Centro de Investigaciones y Estudios en Antropología Social/ Instituto Nacional Indigenista, 1996.

${ }^{4}$ Para Radding, comunidad suele referirse al pueblo indio, pero su significado va más allá de una aldea o ranchería ya que su territorio y población se modifican a través del tiempo. Esta reconstrucción de la comunidad, se realiza a través de sus relaciones económicas, redes de parentesco y liderazgos, definiéndolos como una unidad étnica. Cynthia Radding, 
permanencia como pueblo autóctono y sus transformaciones ecológicas, políticas y económicas. Entre otras aportaciones, la autora destaca la resistencia de los indígenas serranos, mismos que utilizaron todos los medios políticos disponibles para hacer frente a las políticas coloniales; entre estas formas de resistencia, analiza la opción de vivir bajo campana ${ }^{5}$ y en rancherías volantes $^{6}$ (Radding, 1995, p. 98-99). Asimismo explica las alianzas entre líderes indígenas caracterizándolas de ser efímeras con una autoridad limitada sobre sus seguidores inmediatos (Radding, 1995, p. 108). Sin embargo, dicha resistencia conformó lo que posteriormente sería una confederación de líderes ópatas y yaquis. ${ }^{7}$

Hernández Silva (1996) periodiza su obra de 1821 a 1910 haciendo un recorrido histórico del legado colonial del grupo yaqui. El año parte de 1821 ya que, para el autor, la problemática indígena y su insurrección comenzaron una vez terminada la independencia de México a razón de los proyectos liberales de nación, que amenazaba directamente su autonomía política. De esta manera, explica que antes de la independencia, los yaquis eran vistos como corporaciones con propiedades comunales y autonomía heredados de la administración misional, ${ }^{8}$ misma que vio nacer a la cultura yaqui que permeó todo el siglo xix. Aunado a lo anterior, están las nuevas interpretaciones historiográficas cuyos estudios son los textos más actuales que abordan las sublevaciones indígenas en diferentes momentos históricos. Dichos estudios pretenden realizar miradas más integradoras del poder, dando voz y agencia a los indígenas que participaron en los conflictos políticos del xix, otorgándoles nuevos roles políticos y sociales que permitan reconstruir con mayor fidelidad su historia.

Entre el desierto y la sierra. Las naciones O'odham y Teguima en Sonora, 1530-1840, México, Centro de Investigaciones y Estudios Superiores en Antropología Social/Instituto Nacional Indigenista, 1995, p. 15.

${ }^{5}$ Era la opción de vivir fuera de las reducciones indígenas sin el control social que establecían las misiones o instituciones del dominio colonial. Esta opción para vivir fuera del control creó divisiones dentro de la etnia y por lo tanto grupos o familias desertaban de los pueblos de misión viviendo en las rancherías volantes que se caracterizaron por migraciones intraterritoriales. Radding, Entre el desierto y la sierra..., p. 99.

${ }^{6}$ Consistían en pequeños poblados o campamentos de parientes o familias extensas que no permanecían en un solo lugar; funcionó como estrategia de resistencia indígena para eludir el control de los españoles, y que funcionó durante todo el periodo colonial. Radding, Entre el desierto y la sierra..., p. 101.

${ }^{7}$ Radding, Entre el desierto y la sierra..., p. 98-123.

${ }^{8}$ Edward Spicer, Los yaquis. Historia de una cultura, México, Universidad Nacional Autónoma de México, Instituto de Investigaciones Históricas, 1994, p. 26. 
En este tenor, para abordar a los grupos indígenas como sujetos activos y conocer su presencia social, política y cultural en la historia de Sonora del xix Raquel Padilla Ramos, Zulema Trejo Contreras, Dora Elvia Enríquez Licón y Esperanza Donjuan, en Religión, nación y territorio en los imaginarios sociales indígenas de Sonora de 1767 a 1940, retomaron los postulados de Cornelious Castoriadis orientados principalmente al ámbito político. Para lo anterior, acercan su mirada hacia los fundamentos de la cultura de los grupos étnicos en Sonora y la definición-redefinición de las relaciones establecidas al interior de su sociedad. A través de los postulados de Castoriadis dimensionan el grado de autonomía individual y colectiva respecto de las representaciones de una sociedad; es decir la conciencia y la responsabilidad de sus actos en una sociedad en constante transición. Asimismo, comparten el objetivo de rescatar la participación política pacífica dentro del imaginario indígena del periodo de transición colonial al liberalismo.

A pesar del esfuerzo de los autores expuestos anteriormente para explicar las formas de adaptación y reconfiguración sociopolítica entre la sociedad mestiza y la indígena, en la historiografía regional permanece la concepción de la transición entre el Antiguo Régimen y la entrada del liberalismo, se generó una enorme inestabilidad reflejada principalmente en violentas rebeliones indígenas. En este sentido, aunque se realiza un notorio hincapié en las formas pacíficas de adaptación, los autores concuerdan en que fue un proceso que vulneraba las formas de vida de los pueblos indígenas, los cuales se manifestaron a través de resistencias violentas. El postulado anterior ha sido cuestionado por la "ferocidad" de los grupos indígenas ante las amenazas constantes del Estado; lo que a simple vista pareciera una particularidad de la historia del estado de Sonora o del "imaginario historiográfico sonorense". 9

Sin embargo, es innegable que la documentación de la época brinda estas miradas relacionadas con un periodo turbulento en donde los grupos indígenas pactaron, pero también reaccionaron cuando sus demandas no eran tomadas en cuenta. El caso anterior se encuentra reflejado en este trabajo en las insurrecciones indígenas suscitadas en el periodo de 1855 a 1859 en Sonora. El centro de dichas insurrecciones se ubicó en el valle del

${ }^{9}$ Chantal Cramaussel, "Reseña sobre Esperanza Donjuan Espinoza, Raquel Padilla Ramos, Dora Elvia Enríquez Licón y Zulema Trejo Contreras, Religión, nación y territorio en los imaginarios sociales indígenas en Sonora, 1767-1940", Relaciones, n. 142, primavera 2015, p. 324 . 
Yaqui y lugares aledaños, pero también éstas despuntaron en otras zonas del estado. La historiografía local adjudica mayormente dichas insurrecciones a grupos de indígenas aliados a Manuel María Gándara, ${ }^{10}$ que a razón de promesas y relaciones cercanas se unieron al movimiento gandarista ${ }^{11}$ en la búsqueda por recuperar su poder político, sin remitirse a las razones de los grupos indígenas para integrarse.

En este trabajo nos centramos en explicar el origen de dichas sublevaciones a través de los intentos previos de negociación, los intereses particulares que remitían a intereses grupales, la conciencia reflexiva dentro de los grupos, así como el proceso de subalternización por parte del Estado. El panorama anterior conlleva a buscar marcos referenciales que destaquen la participación de los grupos de rango inferior en los conflictos políticos; en este sentido los estudios subalternos buscan "equilibrar" dicha historiografía a través del "otro" de menor categoría, que por distintas razones ha quedado inmerso en la oscuridad de la historia; en este sentido, se

${ }^{10}$ Manuel María Gándara nació en el mineral el Aigame en el municipio de la Colorada en 1801. Su padre fue Juan Gándara, quien fungió en distintos cargos políticos coloniales como el de defensor de indios. En 1828 sus padres, así como sus hermanos más pequeños, fueron expulsados durante dos años fuera del estado. Él se quedó en el estado y a partir de 1837 ocupa cargos políticos como el de gobernador. Durante las décadas de 1840, 1850 y 1860 su actividad política fue acusada en diversas ocasiones de levantar una guerra de castas en el estado. En dichos años, detentó en numerosas ocasiones el cargo de gobernador, así como el de comandante general del Estado. Convivió y adoptó distintas formas de gobierno entre centralismo y federalismo, y siempre se caracterizó por tener una fuerte influencia y relaciones con los grupos indígenas; dichas relaciones se le adjudican tanto a su padre como a las simpatías que guardaba con ciertos líderes indígenas así como sus haciendas del Bámuri y Topahue, a cuyos empleados se les acusaba de defender las causas políticas de Gándara. Murió en Hermosillo en 1878. Francisco R. Almada, Diccionario de historia, geografía y biografía sonorense, Hermosillo, Gobierno del Estado de Sonora/Instituto Sonorense de Cultura, 1990, p. 925-945.

${ }^{11}$ El gandarismo comenzó como un conflicto político entre Manuel María Gándara y José Urrea por la candidatura del estado de Sonora. El origen del conflicto nació en el año de 1837 cuando el presidente Anastasio Bustamante eligió para la primer gubernatura centralista del estado de Sonora a Manuel María de una terna entre éste, Simón Elías González y José Urrea. La inconformidad de Urrea por dicha decisión se reflejó en 1838, cuando destituyó a Gándara y se pronunció en favor del federalismo. Esto trajo consigo un suceso conocido en la historiografía sonorense como el conflicto Gándara-Urrea o gandarismo, que perduró de 1837 a 1846. De 1842 a 1844 el general José Urrea es designado como gobernador y comandante militar del estado de Sonora hasta su destitución en el año de 1845. A partir de este año y hasta 1856 Gándara y sus allegados suben a la gubernatura del estado de Sonora, siendo éste gobernador durante los años de 1847, 1849, 1853, 1854, 1855 y 1856. A pesar del ascenso de Manuel María Gándara, las gavillas conformadas por indígenas asediaron la región hasta el año de 1859. Se descarta que éstas siempre fueran acordes con el gandarismo. 
pretende "democratizarla" y realizar la "rectificación de un núcleo epistemológico" sin el cual no se podría explicar aquella "zona de sombras". ${ }^{2}$

Los estudios subalternos para una mirada compleja del poder

Si bien el nominativo subalterno cuestiona el carácter activo de los indígenas dentro del movimiento, Ranahit Guha destaca que los movimientos campesinos no son sino "movimientos horizontales" que han sido representados como "movilizaciones verticales" a través del discurso historiográfico de la élite, destacando la diversidad social de motivaciones e intereses de sus miembros. Sin embargo, existía un objetivo en común que hacía referencia a la conciencia ante la "noción de resistencia a la dominación de la élite" y cuya problemática principal son las fuentes que den voz al subalterno, dando pie al mito de las "insurrecciones espontáneas o premeditadas" que subyacen en los documentos oficiales. En este tenor, desde la perspectiva de Guha sería difícil señalar un levantamiento que no estuviera precedido por intentos previos de negociación o movilización "menos militante". ${ }^{13}$ La presente investigación plantea el análisis de Guha a través de los movimientos de gavillas, compuestas en su mayoría por grupos de indígenas que mostraban su conciencia a través de la resistencia a la dominación de ciertas autoridades estatales que contrariaban sus intereses. Lo anterior estuvo aunado a intentos previos de negociación; insurrección, cuando no existía el pacto, y políticas estatales que los convirtieron en sectores subordinados.

En este tenor Claudia Salomón Tarquini explica que realizar estudios subalternos no es sólo analizar la resistencia de los actores indígenas, sino los procesos de subalternización y asimilación; la primera se entiende como el proceso mediante el cual ciertas políticas promovidas por el Estado-nación buscaban lograr que los grupos indígenas pasaran a convertirse en sectores subordinados. Esta perspectiva permite el abordaje de procesos históricos protagonizados por sectores como los pueblos originarios, largamente ignorados por las historiografías nacionales, sin limitar el análisis de

\footnotetext{
12 Guillermo Zermeño Padilla, "Condición de subalternidad, condición postmoderna y saber histórico. ¿Hacia una nueva forma de escritura en la historia?”, Historia y Grafía, México, n. 12, 1999, p. 11.47, p. 12.

${ }^{13}$ Ranahit Guha, Las voces de la historia y otros estudios subalternos, Barcelona, Crítica, 2002, p. 10 y 11.
} 
su incorporación al Estado-nación únicamente a las condiciones de subordinación económica. ${ }^{14}$ En este sentido, este trabajo contempla que las legislaciones especiales realizadas durante la gubernatura de Gándara durante el año de 1853-1854 y ejecutadas por Ignacio Pesqueira, una vez estando en el poder, querían propiciar la subordinación política y social de los grupos indígenas; cuestión que se abordará con mayor profundidad en el transcurso de este trabajo.

Lo anterior permite cuestionar las fuentes en las que se han enmarcado los discursos políticos que consideran a los grupos subalternos sin poder de agencia; en este sentido, surgen las siguientes interrogantes: ¿̨los levantamientos indígenas fueron insurrecciones espontáneas sin intentos previos de negociación?, ¿̇existió una conciencia al interior de los de las gavillas de indios?, ¿el Estado promovió políticas que ocasionaron la fragmentación de grupos indígenas, permitiendo que éstos se convirtieran en sectores subordinados?

De forma general cuando a los movimientos sociales se les da este sentido de inmediatez, la rebelión es vista como una acción refleja en contra de factores tales como la privación económica; sin embargo, se deja de lado un elemento que resulta fundamental para conocer el motivo u objetivo que trae de fondo una rebelión y que se refiere a la conciencia reflexiva. Así pues, Guha critica a las historiografías tradicionales por considerar que los movimientos o rebeliones sociales no eran considerados como política; ante esto, el autor propone un acercamiento al tema de la conciencia que rechaza su reducción a la razón y la lógica. ${ }^{15}$

La política y la conciencia, desde su perspectiva, permiten conocer la acción de las clases subalternas destacando que las movilizaciones campesinas fueron un recurso de conciencia reflexiva. Según Guha, "no había nada de espontáneo en esto, en el sentido de ser irreflexivo y no deliberado. El campesino sabía lo que hacía cuando se sublevaba. El hecho de que su acción se dirigiese sobre todo a destruir la autoridad de la elite que estaba por encima de él y no implicase un plan detallado para reemplazarla no lo pone fuera del reino de la política. Por el contrario, la insurgencia afirmaba su carácter político precisamente por este procedimiento negativo que trataba de invertir la situación". ${ }^{16}$ Este ejercicio de conciencia reflexiva

${ }^{14}$ Claudia Salomón Tarquini, "Procesos de subalternización de la población indígena en Argentina: los ranqueles en La Pampa, 1870-1970”, Revista de Indias, v. 71, n. 252, 2011, p. 545-570, p. 547.

${ }^{15}$ Guha, Las voces de la historia..., p. 12.

${ }^{16}$ Guha, Las voces de la historia..., p. 104. 
permitía ser parte de un proceso de construcción de su propia identidad frente a aquel personaje o autoridades que amenazaban sus formas de vida, sus valores o sus sistemas de normas; en este sentido, la unión de un grupo de personas para destituir a un miembro de la élite los hacía que se implicaran en el escenario político de la época.

Para lo anterior, en este trabajo la conciencia reflexiva dentro del grupo no se remite a una convergencia ideológica entre los integrantes cuyas proyecciones eran de índole nacional; sino a la convergencia dentro de un grupo en contraposición a una autoridad o poder estatal que no convenía a sus intereses y que, por lo tanto, era necesario ejecutar una acción hacia ella. Sin embargo, no me remito a un maniqueísmo existente entre la sociedad dominante y los dominados, entre la resistencia y el poder. Es decir, ¿fueron siempre contrapuestos la sociedad mestiza y los grupos indígenas?, ¿existieron momentos de convivencia a razón de pactos y negociaciones que integraban los intereses de ambas? Contrariamente a la percepción del maniqueísmo entre dos sociedades diferenciadas, se busca explicar los elementos que permitieron la posible unificación de intereses materiales. Esta cuestión es visible a través de Manuel María Gándara, miembro del poder estatal que, ejecutando su cargo, realizó políticas que favorecieron a grupos indígenas buscando pacificar las zonas en disputa. Así pues, había medios de negociación exitosos y también la acción social de las parcialidades ${ }^{17}$ y especialmente de las gavillas, ${ }^{18}$ cuando los medios de negociación eran inexistentes.

${ }^{17}$ Unión de personas que se confederan para un fin y como designio anticipado a favor o en contra de algo o alguien. El diccionario de la Real Academia Española para el periodo la define como "reunión o confederación de algunas personas, con un fin determinado, separándose del cuerpo ó de la sociedad a que pertenecían y constituyendo una facción o familia aparte”. En este trabajo, dicha unión tenía su base territorial en el valle del Yaqui y autoridades indígenas constituidas. Hasta el momento, he identificado dos parcialidades en territorio yaqui al revisar la documentación de la época; en ellas se perciben dos divisiones políticas, la primera proveniente de los pueblos de Belem, Huíviris, Ráhum y Pótam, que se conforman como una parcialidad a favor del gobierno estatal en turno, y otra proveniente de los pueblos del interior del valle como Vícam, Tórim, Bácum y Cócorit, considerados como rebeldes y contrapuestos a las políticas estatales; generalmente, en dichos pueblos se encontraba el origen de las sublevaciones del Yaqui.

${ }^{18}$ Conjunto de personas que se forjan en momentos conflictivos políticamente en donde existe un vacío de poder o autoridad indígena que los represente. Éstas aparecen de forma constante una vez extinto el cargo de capitán general para la política estatal, perdiendo la figura de intermediario entre indígenas y autoridades mestizas. Continuamente se les reconoce como "soldados de Gándara” ya que éstos le refrendan su apoyo; particularmente hago referencia a las gavillas representadas por Juan Tánori, autonombrado capitán general, 
En este tenor, desde la perspectiva de Massimo Modonesi la subalternidad y los estudios académicos desarrollados por la escuela de estudios subalternos representada por Ranahit Guha ha sido cuestionada a razón del enfoque reduccionista que provee, al considerar a los dominados y dominantes de forma esencialista que tiende a homogeneizar a sus actores. Asimismo propone asimilar al sujeto en una dimensión subjetiva en la totalidad de su composición de forma unidimensional entre opuestos, aceptación y rechazo de la dominación, espontaneidad o conciencia. Sin embargo, utilizarlo como componente analítico para este trabajo, no significa reconocer en la subalternidad un componente único o esencial, sino la subalternidad como condición y parte de un proceso de desarrollo donde se incluyen combinaciones de aceptación, resistencia, espontaneidad y conciencia. ${ }^{19}$ Lo anterior implica distinguir situaciones y contextos para reconocer las distintas formas y manifestaciones de la subalternidad, misma que es necesario adjetivar en correspondencia con donde es concebida.

El ejemplo más representativo de lo anterior es la contraposición de las políticas liberales provenientes de Ignacio Pesqueira, en donde los grupos subalternos ejecutaron su acción social a través de las gavillas de indios. En este sentido funcionaron como fuente de acción cuando un vacío de poder y representación indígena se fragmentó a razón de nuevas legislaciones, estipuladas por el poder estatal y vistas a través de la subalternización que plantea Salomón Tarquini, donde el cargo del capitán general perdía relevancia política y se le sujetaba a otras autoridades mestizas; asimismo el poder estatal declaraba la acción política y el castigo en contra de los líderes que orientaban las sublevaciones indígenas.

Así pues, los levantamientos no fueron premeditados sin previa negociación y no correspondían particularmente a la búsqueda de intereses inmediatos, sino a la permanencia de autoridades indígenas que los representaban e intermediaban. En este sentido, en este trabajo se trata de explicar las distintas manifestaciones de la subalternidad: el proceso que incluye los

y su hermano Refugio Tánori, así como las de los hermanos Leyva que llevaban a cabo sus acciones en el periodo de 1856 a 1859. A pesar de ser representadas por indios ópatas, dichas gavillas se conformaron según la documentación por indígenas pimas y yaquis.

${ }^{19}$ Massimo Modonesi, Subalternidad, en línea, México, Universidad Nacional Autónoma de México, Instituto de Investigaciones Sociales, 2012 (Conceptos y Fenómenos Fundamentales de Nuestro Tiempo), p. 18. Disponible en: http://conceptos.sociales.unam.mx/conceptos_final/497trabajo.pdf 
intentos previos de negociación, la subalternización por parte del Estado y las sublevaciones indígenas en correspondencia con dicho proceso.

Los intentos previos de negociación

Los cambios políticos más sustantivos para los grupos indígenas en México durante el siglo Xix fueron resultado del nuevo orden liberal establecido en los años de 1854 a $1857 .{ }^{20}$ La revolución de Ayutla, realizada por personajes identificados como "liberales" hablaba de los daños causados por la dictadura de Santa Anna al enajenar La Mesilla; asimismo, establecía la necesidad de que se promulgara una nueva constitución y nuevas consideraciones para establecer el orden liberal frente al tradicionalismo heredado de la época colonial. De tal forma, enmiendas como declarar la igualdad jurídica, la individualización de la propiedad y la división y la repartición de tierras de corporaciones rompieron con las estructuras políticas y económicas de décadas anteriores y obligaron a los grupos indígenas a establecer nuevas bases de convivencia, resistencia y negociaciones ante la inminente fragmentación de sus formas de vida.

El estado de Sonora no quedó indiferente ante el panorama político anterior; durante los años de la revolución de Ayutla la sucesión de varios gobernadores trajo consigo la pugna por el poder entre dos facciones políticas: las aliadas a Manuel María Gándara y las relacionadas con Ignacio Pesqueira. Una vez que este último se establece en el poder, a partir del año de 1856, su ideario liberal trajo consigo proyectos para colonizar los valles del sur del estado, mismos que se llevaron a cabo en el transcurso de su administración, provocando la colonización de los ríos Yaqui y Mayo a través de la fundación de la Colonia Pesqueira en el río Mayo, y la penetración a territorio Yaqui en $1859 .{ }^{21}$

En este sentido, las bases de convivencia, resistencia y negociaciones estuvieron reflejadas durante la década de 1850 en Sonora a través de distintas perspectivas; si bien existieron estrategias por parte del gobierno estatal para menguar las sublevaciones indígenas, las insurrecciones fueron

${ }^{20}$ Andrés Lira y Anne Staples, “Del desastre a la reconstrucción republicana, 1848-1876”, en Nueva historia general de México, México, El Colegio de México, 2010, p. 448.

${ }^{21}$ Iván Revilla Celaya, Utopías liberales: proyectos de colonización y rebeliones indígenas en los valles del Yaqui y del Mayo, 1853-1867, Hermosillo, El Colegio de Sonora, [2014] p. 93-105. 
una constante sobre todo durante la década de 1850. Parte de dichas estrategias para menguar insurrecciones se llevó a cabo a través de pactos entre autoridades indígenas y autoridades estatales; de tal forma, existieron cargos como el de capitán general, que funcionó como un intermediario entre ambas sociedades, con la finalidad de pacificar sus zonas de influencia apelando al apego a las leyes y el bienestar de la nación. ${ }^{22}$

El cargo de capitán general fue traído por los españoles durante el proceso de colonización al asentarse en territorio mexicano; a decir de José Marcos Medina Bustos, llevaba consigo una historia de conquista al ser utilizado por las huestes españolas en la expulsión de los árabes. La práctica anterior fue traída por los españoles durante la Colonia con una particularidad: los indígenas conformaban parte de las huestes y eran quienes recibían dichos privilegios como destinar caballos y territorios a quienes participaran al lado de los españoles. En zonas de difícil acceso, las instituciones fronterizas adoptaron este cargo como una fuente de defensa ante los embates de los grupos nómadas como los apaches. ${ }^{23}$ Históricamente era nombrado un capitán general para cada una de las etnias, el cual era independiente del misionero y su mandato remitía directamente al poder real, que lo dotaba de autonomía y autoridad ante su grupo. Lo anterior ocasionó que su mandato tuviera mayor poder que los alcaldes o gobernadores de los pueblos.

Dicho cargo fue utilizado por los españoles con ciertas características: en el grupo ópata fue utilizado para guiar y auxiliar a las compañías presidiales ante el embate de los apaches. En el caso de los yaquis, el cargo fue intermitente ya que sólo participaba en la estructura militar colonial, cuando éste era solicitado. ${ }^{24} \mathrm{~A}$ partir del régimen misional y el advenimiento de México como país independiente, los capitanes generales lograron mayor relevancia en la estructura política y militar, ya que al no tener instancias oficiales en las cuales desarrollar organización militar, éstos funcionaron

${ }^{22}$ Lucía García Rivera y Zulema Trejo, "Entre el poder y la autoridad: Mateo Marquín, capitán general de yaquis y mayos de 1843 a 1857”, Relaciones. Estudios de Historia y Sociedad, v. 39, n. 153, enero 2018, p. 227-259, p. 225.

${ }^{23}$ José Marcos Medina Bustos, "Cargos militares indígenas en la transición del antiguo régimen al liberalismo”, Revista de Ciencias Sociales, Universidad Nacional de Quilmes, Argentina, año 3, n. 20, 2011, p. 29-48.

${ }^{24}$ Ana Luz Ramírez Zavala, "De todo se han aprovechado esos hombres políticos y revolucionarios”. Los yaquis durante el proceso de formación del Estado posrevolucionario: negociación y cambio cultural, 1920-1940, tesis de doctorado en Historia, México, El Colegio de México, 2014. 
con autonomía ante las propuestas políticas a nivel nacional. Para el siglo XIX, el yechim no sólo organizaba las actividades militares, sino que cobró importancia política frente a las otras autoridades indígenas, como la de los cobanahuas o gobernadores. A decir de Hernández Silva, cobró cierta prestancia hacia la defensa de sus pueblos, adquiriendo supremacía sobre los gobernadores indígenas. ${ }^{25}$ A pesar de su trabajo exitoso en la intermediación de conflictos, las sublevaciones de indios tomaron mayor fuerza una vez extinto el cargo de capitán general a partir de 1855 y 1856.

En este tenor, una forma de hacer referencia a las insurrecciones era a través del término gavillas, ${ }^{26}$ mismo que se utiliza de forma más recurrente a la muerte del capitán general Luis Tánori, ${ }^{27}$ haciendo referencia principalmente a las incursiones que causaban robos y destrozos en las haciendas cercanas al camino de Hermosillo; principalmente, fueron lideradas por el cabecilla ópata Juan Tánori y Pedro Leyva. En el caso del valle del Yaqui y Mayo, los términos utilizados seguían siendo "sublevados al orden" siendo suscitados los levantamientos durante el decaimiento del poder de Mateo Marquín ${ }^{28}$ después de 1855. Así pues, las sublevaciones indígenas

${ }^{25}$ Héctor Hernández Silva, Insurgencia y autonomía. Historia de los pueblos yaquis: 18211910, México, Centro de Investigaciones y Estudios Superiores en Antropología Social/ Instituto Nacional Indigenista, 1996.

${ }^{26}$ La definición de gavilla usada en el periodo de análisis que se encuentra en el tesoro lexicográfico de la Real Academia de la Lengua Española; la definición proviene de los diccionarios de 1843 a 1852 como "La junta de muchas personas y comúnmente de baja suerte sin orden ni concierto”. Posteriormente, para el año de 1853 la definición se refiere de igual forma a una "cuadrilla, junta o reunión de malhechores, ó de otra gente por el estilo: por manera que gavilla se toma siempre en mala parte: así es que basta decir, es gente de gavilla, para dar á entender las malas cualidades de las personas de quienes se hable. Á veces se usa esta misma voz para desprestigiar una faccion, reunión, etc. Aunque sus individuos no ejerzan acciones malas".

${ }^{27}$ Luis Tánori fue un indígena ópata que fungió como capitán general de ópatas y pimas a partir del año de 1842. Durante el año de 1843 él fue intermediario entre los sublevados del ex gobernador Manuel María Gándara y el gobierno del general Urrea; intercambió correspondencia con los pueblos del río Sonora, y el capitán general del río Mayo con la finalidad de intermediar el levantamiento. Continuamente, solicitaba a los pueblos del río Sonora que se conservara el orden, la tranquilidad y la fidelidad ante las autoridades estatales; asimismo, pedía armamento para detener las incursiones apaches. En 1854 Luis Tánori fue asesinado al detener una incursión apache.

${ }^{28}$ Mateo Marquín fue un indígena yaqui que tomó el cargo de capitán general en el año de 1842 después de la muerte de Juan María Jusacamea y durante el gobierno de José Urrea. En la documentación de este año, se le menciona como "la primera autoridad del río Yaqui" firmando como capitán general. Las funciones que desempeñaba como capitán general eran pacificar la zona del río Yaqui y Mayo, y comunicar a las autoridades estatales si existía algún 
que durante el periodo de los capitanes generales ópatas y yaquis -Tánori y Marquín- estuvieron en relativa paz a excepción del año de $1846,{ }^{29}$ comenzaron sus incursiones en el Yaqui y en territorio ópata al desaparecer la mediación que establecía dicho cargo.

Un ejemplo de cómo intermediaba el cargo de capitán general fue el caso de 1855 en el que indios pimas, pápagos y ópatas fueron continuamente solicitados por la Guardia Nacional ${ }^{30}$ para retener las incursiones apaches, mismas que eran capitaneadas por el capitán general. Después de la muerte de Luis Tánori existieron grupos de ópatas que no estaban de acuerdo con participar en la Guardia Nacional para combatir apaches; ${ }^{31}$ es el caso del indígena Miguel Vázquez de Opodepe, quien es acusado por el general Pesqueira por la "sedusión [sic] que introdujo entre los cabos de la compañía". ${ }^{32}$ De esta forma explica la "perversidad de sentimiento" de éste, que influye a favor del enemigo en común que ha causado tantos males al departamento de Sonora. ${ }^{33}$

movimiento en contra del gobierno en turno. En el año de 1846 intermedia exitosamente un levantamiento del indígena mayo Miguel Esteban, quien se pronunciaba como capitán general del Mayo. Dominaba el lenguaje de la época haciendo alianzas con los personajes que se encontraban en la escena política; entre ellos, continuamente se le relacionaba con Manuel María Gándara. De 1854 a 1856 se le distinguió por acaudillar levantamientos indígenas en la zona del río Yaqui y Mayo en defensa de los territorios del Babójori y Aguacaliente, mismos que estaban siendo amenazados por la familia Íñigo durante el gobierno de Ignacio Pesqueira. Murió en 1856.

${ }^{29}$ En este año, un grupo de yaquis y ópatas se unificaron en contra del capitán general Mateo Marquín, siendo liderados por el mayo Miguel Esteban. La enmienda de la sublevación fue la demanda del cargo de capitán general para el río Mayo no reconociendo la demarcación política que unificaba la autoridad de Mateo Marquín en el Yaqui y el Mayo. Frente a lo anterior, Mateo Marquín logró mediar entre la sublevación y las autoridades estatales otorgando el perdón a los sublevados al orden a través de Manuel María Gándara y de confinar a Miguel Esteban y su familia a una de las haciendas de este último. Lucía García Rivera, Liderazgos, pactos e insurrecciones. Líderes indígenas y el poder estatal, 1843-1859, tesis de doctorado en Ciencias Sociales, Hermosillo, El Colegio de Sonora, Estudios Históricos de Región y Frontera, 2016, p. 120.

${ }^{30}$ Estructura militar propia independiente de la Guardia Nacional y bajo jurisdicción del comandante militar del estado. Estas fuerzas se consideraban auxiliares de la federación y se utilizaban en el combate a los apaches; estaban directamente bajo el mando de un capitán general, cargo ocupado por un miembro del grupo indígena correspondiente designado por el gobierno estatal.

${ }^{31}$ Archivo General del Estado de Sonora, Fondo Ejecutivo. Ramo Prefecturas (en adelante, AGES, $F E, R P$, t. 283: Altar, octubre 30 de 1855.

${ }^{32}$ AGES, FE, RP, t. 283: Ures, julio 18 de 1855.

${ }^{33}$ AGES, FE, RP, t. 283: Ures, julio 18 de 1855. 
Enterado de ese suceso, como lo manifesté a U., mandé tocar asamblea, pero dificultándose la reunión de la fuerza que debía mover sobre los enemigos ya por hallarse algunos urbanos ausentes, ya principalmente por la sedusion que introdujo el indígena Miguel Vázquez entre los cabos de la compañía, llamándome así la atención no me fue posible hacer la marcha con la impetuosidad que deseaba, y hube de verificarlo a las cinco de la tarde del mismo día, con treinta hombres entre urbanos y auxiliares. ${ }^{34}$

Así pues, para buscar que estos indios fueran reincorporados de nueva cuenta a las filas de la Guardia Nacional se les otorgaban pagos por matar apaches, y la posibilidad de elegir a sus tenientes generales. En este mismo sentido, se encuentra el caso del nombramiento del teniente general de los ópatas en Sahuaripa, donde la prefectura a través de José María Arvayo solicitó al gobierno del estado que reconocieran el nombramiento que hicieron los indígenas de ese distrito a Manuel Cruz, quien obtuvo una "mayoría absoluta de votos" entre ellos. Para lo anterior, realizaron una reunión los vocales indígenas de cada pueblo que representaban "la voz de todos los demás”, quienes realizaron su elección hacia este jefe reconociéndolo como "jefe de todos los indígenas":

Para dar el debido cumplimiento a la estimable comunicación de VS fecha 4 de [i? comunicó orden esta prefectura a los Pueblos del Distrito de [ilegible]go, en que hay indígenas, para que se reuniesen éstos en esta cabecera con el fin de nombrar un Teniente Gral. de indígenas para facilitar sus movimientos en persecución de los bárbaros. El día 20 del corriente se reunieron en esta villa dos bocales [sic] indígenas de cada Pueblo, quienes representaban la voz de todos los demás, y habiéndoles hecho entender esta prefectura que podían proceder al nombramiento de un teniente gral., en la persona que gustasen, lo verificaron por medio de elección, recayendo el nombramiento por mayoría absoluta de votos en el Indígena del Pueblo de Ponida Manuel Cruz, a quien se lo hi[ce pr] esente, quedando entendidos de ello los referidos vocales que lo reconocerán y obedecerán como a tal Jefe todos los indígenas. ${ }^{35}$

Con los ejemplos anteriores se percibe la posibilidad de establecer acuerdos entre las autoridades estatales y los grupos de indígenas; el motivo

${ }^{34}$ AGES, FE, RP, t. 283: Ures, julio 18 de 1855.

35 AGES, FE, RP, t. 285: Nombramiento de Tte. Gral. de los ópatas. Sahuaripa, e. 214.61", Sahuaripa, mayo 30 de 1856. 
principal para dichos acuerdos era que se reincorporaran a las correrías hechas contra el enemigo apache. Sin embargo, los indígenas postulaban a sus propios representantes considerando que eran portadores de la "voz de todos los demás”. En este sentido, son visibles los intentos de negociación entre autoridades estatales y líderes indígenas, así como una posible conciencia reflexiva dentro del grupo, al negarse a participar dentro de la Guardia Nacional para detener las incursiones apaches, si no era reconocida la autoridad indígena que ellos demandaban.

Desde esta perspectiva, la conformación de parcialidades se realiza a razón de intentos previos de negociación entre conflictos de autoridades estatales y autoridades indígenas. En la historiografía argentina, el término se ha utilizado para denominar la presencia de unidades étnico-políticas que ocuparon ambientes ecológicos diferenciados; en este sentido se hace un uso equivalente a los términos unidad política, agrupación, cacicazgo y parcialidad para referirse a seguidores de un cacique o grupo mayor. ${ }^{36}$ Así pues, la parcialidad hace referencia a la unión de algunas personas que se confederan para un fin, separándose del común y formando un cuerpo aparte.

En este trabajo, las parcialidades de indios son los grupos al interior de la etnia, los que a través de su apoyo otorgan legitimidad a un líder y cuyas acciones están vinculadas, presentando un comportamiento pacífico cuando existen pactos establecidos entre el líder y el poder estatal y un proceder insurrecto cuando el pacto falla y no vela por sus intereses. A partir de lo anterior, he localizado dos parcialidades yaquis que constantemente aparecen en la documentación del periodo: aquellas que provienen de los "cuatro pueblos de la parte de abajo", ${ }^{37}$ que según las descripciones de la época de parte de las autoridades estatales "son pacíficos y con bastante civilización, su fidelidad y sumisión al gobierno es bien notoria y se debería contar con ellos para establecer una población”. ${ }^{38}$ Por otra parte, está la parcialidad de los "pueblos del interior" de "Bacum, Bicam y Tórim"39 que se distinguen por la continua contraposición a las autoridades estatales.

${ }^{36}$ Ingrid de Jong, “Armado y desarmado de una confederación: el liderazgo de Calfucurá en el periodo de organización nacional”, Quinto Sol. Revista de Historia Regional, n. 13, 2009, p. 11-45, p. 18.

${ }^{37}$ Hace referencia a los pueblos yaquis de Belem, Huíviris, Raum y Pótam.

${ }^{38}$ AGES, FE, Oficialía Mayor, caja 45, tomo 160, 25 de septiembre de 1846.

${ }^{39}$ Idem. 


\section{Mapa 1}

\section{LOS OCHO PUEBLOS TRADICIONALES YAQUIS}

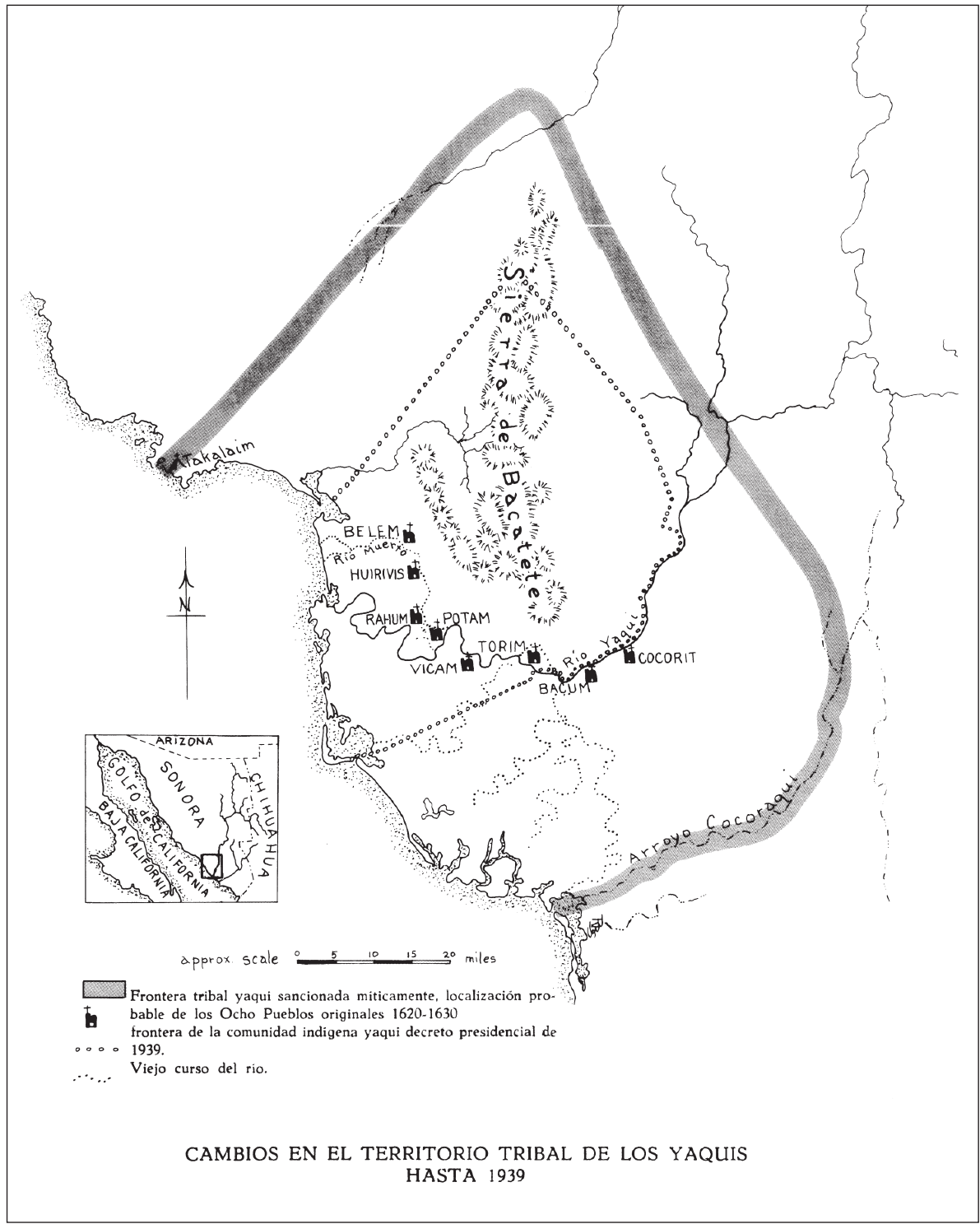

Fuente: Edward Spicer, Los yaquis. Historia de una cultura, México, Universidad Nacional Autónoma de México, Instituto de Investigaciones Históricas, 1994, p. 33. 
Raquel Padilla y Zulema Trejo han planteado que la diferenciación económica y geográfica entre ambas parcialidades correspondía a que en Pótam, Huíviris, Ráhum y Belem enfocaban su producción hacia la pesca y la explotación de salinas, mientras que los pueblos de Cócorit, Bácum, Tórim y Vícam se especializaban mayormente en la agricultura; ${ }^{40}$ de tal forma, para esta parcialidad resultaba fundamental la cuestión del territorio, pues vivían de él. El acto más representativo de lo anterior, se suscitó en el año de 1854 cuando los "pueblos del interior" demandaron ante la gubernatura del estado de Sonora, la usurpación del territorio del Babójori y Aguacaliente por Manuel y Fernando Íñigo, quienes habían prometido establecer una maquinaria de mantas y abrir una toma de agua para los pueblos aledaños. Lo anterior produjo una serie de insurrecciones, mismas que trataron de ser mediadas entre el alcalde mayor del Yaqui, el poder estatal a través del cargo de subprefecto del río y el capitán general Mateo Marquín.

Durante este momento, las parcialidades se conformaron para pactar con el estado políticas que favorecieran sus intereses de grupo; en el caso del yaqui las parcialidades de "los pueblos interior" legitimaron a Mateo Marquín como intermediario entre la defensa del territorio del Babójori y Aguacaliente, ofreciéndole apoyo en sus acciones. En este sentido, optaron por unir sus esfuerzos al capitán general quien, a razón de la salida de Gándara del poder, veía peligrar sus intereses personales ante el gobierno de Pesqueira. De tal forma, las parcialidades funcionaron por intereses particulares que remitían a intereses de grupos de personas quienes mostraban oposición cuando no se veían favorecidos por las políticas estatales; en dicha dinámica, legitimaban cuando era conveniente a autoridades indígenas que consideraban que los representaban y eran intermediarios eficaces con sus demandas.

En el caso de los ópatas, las parcialidades de indios al interior de la etnia funcionaron a través de la representación de un jefe o líder establecido por ellos; en este caso, Luis Tánori fungió como representante y una vez extinto su cargo de capitán, grupos ópatas se negaban a participar en la Guardia Nacional cuyo objetivo principal era combatir a los apaches. Sin embargo, a través del prefecto José María Arvayo, y por orden de Ignacio

${ }^{40}$ Raquel Padilla y Zulema Trejo, "Los ocho pueblos como concepto", en Conflicto y armonía, etnias y poder civil, militar y religioso en Sonora, México, Instituto Nacional de Antropología e Historia, 2009, p. 195-212, p. 197-198. 
Pesqueira, se nombró un teniente general ${ }^{41}$ por mayoría de votos entre los vocales indígenas de cada pueblo ópata convocando finalmente al indígena Manuel Cruz para que le fuera otorgado el nombramiento de ese cargo.

Asimismo, resulta relevante resaltar que las parcialidades no sólo se conformaron en el periodo de estudio del presente trabajo, sino que éstas funcionaron en distintos momentos, sobre todo, cuando se contrapusieron al Estado. Un ejemplo de lo anterior es el Porfiriato, enmarcado en las guerras yaquis encabezadas por Juan Maldonado Tetabiate. Su movimiento derivó en una guerra de guerrillas las cuales fueron congregadas en la sierra y eran visibles para el Estado a través de la división yaqui entre indios mansos y broncos, quienes conservaron sus armas y postura rebelde. En este entendido, la base social de la lucha estuvo conformada por el apoyo material que otorgaban los indios mansos, que trabajaban en las haciendas cercanas así como en la construcción de las vías del ferrocarril, a los indios broncos. Esta forma de rebelión o guerra de guerrillas se convirtió en una resistencia compleja y costosa para el gobierno porfirista, que propició posteriormente la deportación masiva de los yaquis a otras zonas del país.

La subalternización al interior de los grupos

Para explicar el proceso de subalternización que vivieron los grupos indígenas ante el poder estatal, analizaré la "Ley para los pueblos indígenas de Sonora”, que se estableció en el año de 1853. Dichas legislaciones se basaron en las leyes de los pueblos indígenas emitidas en 1828 y $1847,{ }^{42}$ en

${ }^{41}$ Para lo anterior, cabe resaltar que la elección del cargo de "teniente general" era a razón de la desaparición del capitán general, misma que había sido estipulada en 1853 y confirmada con los decretos de Pesqueira en 1857; ambos preceptos se estudiarán con detenimiento posteriormente para ejemplificar el proceso de subalternización por parte del Estado.

${ }^{42}$ Dichas leyes provenían de legislaciones realizadas por el Estado Interno de Occidente en 1828 que comprendía los estados de Sonora y Sinaloa. Después de su escisión en 1830, algunas legislaciones para los grupos indígenas quedaron vigentes siendo la "Ley especial para el gobierno de los pueblos indígenas" una de ellas y manteniendo su vigencia de 1828 a 1847. En 1847 el gobierno de Sonora la derogó y promulgó la "Ley para los pueblos indígenas de Sonora" que tuvo una duración de seis años. Zulema Trejo, "Leyes especiales para el gobierno de los pueblos indígenas de Sonora, 1831-1853”, Fronteras de la Historia, Instituto Colombiano de Antropología e Historia, Bogotá, Colombia, v. 18, n. 2, julio-diciembre 2013, p. 105-131, p. 114. Finalmente, en mayo de 1853 se publica oficialmente la "Ley para el gobierno de los pueblos yaquis" que en el artículo 11, n. 242, establece que "No habrá 
donde se establecía que el cargo de capitán general tenía carácter vitalicio, extinguiéndose al morir las personas que lo ocupaban al momento de promulgarse la ley. Esas personas eran, en ese momento, el yaqui Mateo Marquín y el ópata Luis Tánori. Por otra parte, las mismas legislaciones establecieron cargos ocupados por no indígenas que tuvieron como objetivo la demarcación del valle del Yaqui, entre ellos, el cargo de subprefecto del valle del Yaqui, que será una constante en la pugna por el poder entre éste y el capitán general, Mateo Marquín.

En este periodo se destacan las legislaciones especiales para los grupos originarios, funcionando como fuentes de negociación con líderes y parcialidades indígenas. La promulgación coincidió con el ascenso de Manuel María Gándara al poder del estado en 1853, en donde fue pieza fundamental tener a los mayos bajo control, extendiendo el poder militar del capitán general del Yaqui a territorio mayo. Asimismo, se restableció la organización militar indígena abolida en 1828, por lo que se crearon nuevos cargos como el de subprefecto y los jueces de paz, así como la conservación de los cargos de alcalde mayor y gobernadores. ${ }^{43}$

Es importante destacar que el periodo de estabilidad relativa entre autoridades mestizas e indígenas dio margen para realizar legislaciones especiales que garantizaran el orden y la tranquilidad de la zona, donde se delimitaba la estructura del gobierno civil y militar que debía existir en el Yaqui. La creación de nuevos cargos como la subprefectura y los jueces de paz de la zona del Yaqui, así como la permanencia de los tradicionales, como alcaldes, gobernadores y capitanes generales, buscaban según Zulema Trejo ser una "pieza legislativa de transición encaminada a convertir los ocho pueblos tradicionales en ayuntamientos", lo cual proveía la posibilidad de integrar finalmente a los grupos indígenas a la sociedad mestiza que se estaba conformando en ese momento. ${ }^{44}$

Sin embargo, al interior de los yaquis los efectos de esas legislaciones fueron otros: las diferencias al interior de la etnia de los cargos de alcaldes, gobernadores y capitán general se vieron reflejadas en una pugna por el poder. En este sentido, si bien las legislaciones de 1853 buscaban delimitar la estructura civil y militar de los yaquis al imponer un nuevo cargo sobre

capitanes ni tenientes generales en los pueblos indígenas, a ecepción de Mateo Marquín y Luis Tánori, cuyos títulos ha confirmado el Gobierno General, pero sin mas facultades que cumplir las órdenes del Gobierno que las autoridades de su resorte les comuniquen".

43 Trejo, "Leyes especiales...”, p. 116.

${ }^{44}$ Trejo, "Leyes especiales...”, p. 117. 
la figura del capitán general a través de la subprefectura, lo que se percibe en la documentación es una constante falta de acuerdos entre autoridades indígenas acerca de qué cargo tenía mayor poder y relevancia. Asimismo, la figura del subprefecto del río Yaqui produjo un nuevo intermediario no indígena que mediaba entre las autoridades estatales y las étnicas, apelando constantemente en contra del poder de acción que el capitán general del Yaqui tenía. ¿Fue este el propósito original de las legislaciones?, ¿ise trataba de minar a las autoridades étnicas y fragmentar su poder?

Posiblemente las legislaciones establecidas entre Manuel María Gándara y los capitanes generales buscaban pacificar y otorgar apoyo a las decisiones del grupo gandarista en el poder estatal. Sin embargo, una vez terminado su periodo, y con Pesqueira reconocido por promover políticas radicales en torno a los grupos indígenas, las legislaciones fueron utilizadas como instrumento para convertirlos en sectores subordinados al poder estatal, eliminando cargos como el de capitán general y anteponiendo otros como el de subprefecto del río.

Un ejemplo de lo anterior fueron la introducción del "régimen municipal bajo sus leyes establecidas” por parte de Manuel María Gándara. En dichos decretos, se enunciaba que fueran regidos por sus autoridades tradicionales, fungiendo como capitán general Mateo Marquín; el decreto era ambiguo, pero daba reconocimiento a sus autoridades. Por lo anterior, dos años después, una vez que Pesqueira se estableció en el poder, a través del mismo régimen municipal del 14 de enero de $1857,{ }^{45}$ desconoció el sistema de elección en asamblea de los ocho pueblos; nombró a un alcalde mayor para los pueblos del río, y lo más relevante, ordenó la disolución de la milicia, el desarme de los yaquis y la abolición del cargo de capitán general. Ana Luz Ramírez analiza lo anterior mencionando que posiblemente las adecuaciones al régimen municipal realizadas por Pesqueira eran consecuencia de la alianza de grupos yaquis con los hermanos Gándara; así pues, castigaba su actuar con dichos decretos; asimismo, permitía a los "yaquis fieles" integrarse a las fuerzas auxiliares del estado. ${ }^{46}$

Ante lo anterior cabe el cuestionamiento de si persistieron algunos cargos políticos indígenas durante el gobierno de Ignacio Pesqueira. Pro-

45 AGES, FE, t. 19, R.: Yaquis y mayos, Ignacio Pesqueira a Rafael A. Corella, 14 de enero de 1857, y Rafael A. Corella a Ignacio Pesqueira, Tórim.

${ }^{46}$ Ana Luz Ramírez, "Cambios en la estructura militar yaqui durante el siglo XIX”, Primer Congreso Internacional de los Pueblos Indígenas de América Latina, Siglos XIX-XXI. Octubre de 2013, Oaxaca, p. 9-10. 
bablemente éste no buscaba el enfrentamiento directo con las autoridades indígenas establecidas en las zonas del valle del Yaqui y el Mayo, así como en la zona ópata. En este sentido, buscó establecer buenas relaciones con los opositores a las autoridades que habían ejercido los anteriores capitanes generales Luis Tánori y Mateo Marquín. Así pues, para el valle del Yaqui y el Mayo, se establece que el pago de los sueldos del alcalde mayor del río Mayo, Julio Moroyoqui, ${ }^{47}$ para que éste no renuncie a su cargo como lo había anunciado: "Suspenso de mis sueldos [...] de un año y cinco meses y cuyo importe es mas de quinientos pesos, me veo presionado por las necesidades y escaces de mi familia a hacer ante V. S. la formal renuncia de mi empleo, y suplicarle que si estuviere en sus facultades se sirva admitírmela, y si no recomendarla para que se me conceda esta gracia por V. S. el gobernador del estado". 48

Este grupo de autoridades indígenas facultadas por Pesqueira hacía referencia al alcade mayor y al comandante de milicias D. Juan José Valenzuela, "todos sugetos que pertenecen al orden y discenirmiento de las leyes y no comprende esta prefectura por que crimenes pueden venirseles a castigar [...] como son buenos ciudadanos del orden instituido". ${ }^{49}$ La confusión anterior de las autoridades estatales se refiere a la reunión en el Babójori por parte de Mateo Marquín y 600 hombres que, según mencionaban, "iban a sacarlos del río". Hay que señalar que para este momento se vivía un clima de tensión en el poder estatal ya que el gobierno de José de Aguilar favoreció a Pesqueira estableciéndolo como gobernador sustituto del estado y creando disputas políticas entre el grupo de Gándara y el de Pesqueira.

A partir de lo anterior, las insurrecciones de indios llevadas a cabo en los años de 1856 y 1857 en valle del Yaqui y el Mayo guardan correspondencia de una acción social con orientaciones políticas favoreciendo a un personaje como Manuel María Gándara que, durante su estancia en el poder, mantuvo y pactó con Mateo Marquín, aceptando su intermediación en los conflictos que se suscitaban. Sin embargo, para finales de 1856 sin Tánori y Marquín en la escena política, sin la predominancia de Manuel María Gándara en el poder estatal y un nuevo allegado al poder como Ignacio

${ }^{47}$ AGES, FE, RP, t. 285, doc. 013561: Ures, mayo 21 de 1856.

${ }^{48}$ AGES, FE, RP, t. 285, doc. 013559: Pueblo de Curimpo, 6 de mayo 1856.

${ }^{49}$ AGES, FE, RP, t. 285, doc. 013577, 12 de junio de 1856. 
Pesqueira, ¿cuáles fueron las instancias políticas de los grupos yaquis y ópatas para pactar?

Sin medios de negociación: las insurrecciones de indios

Posteriormente a la muerte de Mateo Marquín en agosto de 1856, ocasionada por un enfrentamiento a las fuerzas pesqueiristas, ${ }^{50}$ la sublevación en el Yaqui siguió su curso; la diferencia estribaba en que ésta estaba directamente vinculada con los gandaristas. En otra parte del estado, en noviembre de 1856 cercano a las haciendas de Chino Gordo y Topahue en el camino de Ures a Hermosillo los bandidos capitaneados por Pedro Leyva entraron a la hacienda de los Monteverde robando, pólvora, fusiles y caballos; dichos hombres decían eran "soldados de Gandara" y que "sólo sus gefes y no él, debian disponer de nuestra suerte". ${ }^{51}$ Esta fue una incursión menor - de 35 hombres- en donde se comenzaba a hacer mención de Pedro Leyva que, para 1859, será una constante en la documentación. Al parecer, tenía como objetivo alimentar de parque y fusiles a los gandaristas y los encargados de hacer ese trabajo, fueron los hermanos Leyva junto al servicio de Topahue, hacienda de Manuel María Gándara, según lo establece Fernando Rodríguez, administrador de la hacienda a quien tomaron preso:

Ynfiero q la mayor parte de la gente q vino à asaltar esta hacienda, pertenece al servicio de la de Topahüe, porq. en la misma hacienda, cada uno de los que se decian soldados, fue tomando su casa: otros (y estos eran yaquis) fueron luego entregados a los mayordomos é inmediatamente se pusieron a trabajar; de suerte q. de treinta y tantos hombres q. vinieron a esta hacienda al paso por la de Topahüe quedaria reducida esa fuerza á cosa de doce hombres. ${ }^{52}$

El camino de Ures a Hermosillo que recorrían las gavillas de los hermanos Leyva tenía como centro de operaciones la hacienda Topahue; así

${ }^{50} \mathrm{El} 4$ de agosto Pesqueira se dirigió a Ures para combatir a una partida de ópatas y yaquis; después de un tiroteo en el que murió Mateo Marquín, cayó la plaza en manos de Pesqueira quedando en su poder armamento y 300 prisioneros. Juan Antonio Ruibal Corella, "La época de la Reforma", Historia general de Sonora, 2a. ed., 6 v., Hermosillo, Instituto Sonorense de Cultura, 1997, v. III, p. 159-160.

${ }^{51}$ AGES, FE, RP, t. 285, f. 261, noviembre 1 de 1856.

${ }^{52}$ AGES, $F E, R P$, t. 285, f. 261, noviembre 1 de 1856. 
pues son perseguidos por Pesqueira como sirvientes de Gándara. Sus robos hacían referencia a cuestiones de fusiles, semovientes pero también personales, como alcohol, quesos y plata. Para este momento, los hermanos Gándara, especialmente Antonio Gándara manifestó "no tener ingerencia ninguna en la revolución y encargándome q. si á mi llegada a casa notaba algún desfalco en los intereses, q. fuese ocasionado por los q. la asaltaron, se lo manifestase p. haser q. se me devolviese todo". ${ }^{53}$

¿Qué relación guardaban las sublevaciones anteriores con una acción subalterna? Si bien la documentación demuestra que los seguidores de Leyva posiblemente aprovecharon las sublevaciones del Yaqui para vincularlos con sus fines, las sublevaciones del Yaqui ya venían fraguándose por lo menos dos años antes de estos acontecimientos. Dichas sublevaciones tenían objetivos definidos como la defensa de los terrenos del Babójori y Aguacaliente en donde se contraponía la autoridad de dos personajes: el alcalde mayor y el capitán general. Sin embargo, para junio de 1857 se percibe en la documentación una unión de los "ocho pueblos" que a José Sandoval, prefecto del distrito de Guaymas en 1857, le parece "que robarian lo mismo que a ellos les han robado sus intereses” y que sólo se lanzarían en armas "no como la vez pasada que a hora tenian quien los dirigiera y contaban con brazos fuertes" y "solo se alzarian en un movimiento a menos que éste fuera en general en los pueblos". ${ }^{54}$

¿A qué se referían las menciones anteriores? Posiblemente era perceptible la división del poder entre el alcalde mayor y el capitán general haciendo la sublevación del Yaqui más débil; sin embargo, en este momento contaban con menos aliados políticos y un enemigo común en el poder estatal: Ignacio Pesqueira. Para ratificar la "enemistad" de Pesqueira, no solamente fueron las acciones ejecutadas para colonizar los territorios del Babójori y Aguacaliente estableciendo ahí un cuartel general comandado por Jesús García Morales, sino el envío de una circular que se remitía a castigar a los cabecillas de gavillas que habían participado en julio de 1856 y noviembre de $1857 .{ }^{55}$ En este tenor, Iván Revilla ha destacado que dichas sublevaciones yaquis estaban directamente relacionadas por la colonización de sus territorios provocada durante la administración de Pesqueira. Asimismo, que el apoyo a los gandaristas les permitió "redimensionar sus

${ }^{53}$ AGES, FE, RP, t. 285, f. 261, noviembre 1 de 1856.

${ }^{54}$ AGES, FE, RP, t. 19, exp. 2, doc. 013861: Álamos, agosto 15 de 1857.

${ }^{55}$ AGES, FE, RP, t. 345, t. 345: Circulares, Gobierno del Estado, Ures, julio 14 de 1859. 
rebeliones, al extenderlas a territorios más allá de sus pueblos tradicionales" y, de la misma forma, obtener recursos como armas, alimentos y municiones para mantener la defensa de su territorio. ${ }^{56}$

A partir de la toma definitiva de la gubernatura en agosto de 1857 , Pesqueira tenía algunas tareas pendientes más allá de las insurrecciones indígenas y la acción de gavillas. Las incursiones no eran particulares de los grupos apaches y la serie de robos que causaban a los pueblos se fue al extremo de llegar algunos a estar semidespoblados. Norma de León analiza la falta de población en el estado desde la década de 1840 por distintos factores: la fiebre del oro en California, la guerra contra Estados Unidos de 1846 a 1848, epidemias y conflictos armados entre facciones políticas. ${ }^{57}$ Sin embargo, el nuevo mandatario, quien ya había asumido el cargo de gobernador sustituto en 1856, enfrentaba como "reto apremiante la precaria situación fronteriza, los conflictos indígenas y la inseguridad derivada de estas dos situaciones"; ${ }^{8}$ en este sentido, Pesqueira se erigía en hombre fuerte capaz de imponer el orden y un gobierno estable en apoyo de los sectores liberales y comerciantes del estado.

De la misma manera que en el valle del Yaqui y el Mayo, en la zona ópata las autoridades pesqueiristas buscaron tener autoridades indígenas de su confianza; tal es el caso del capitán del pueblo de Ónavas, Domingo Jiménez, que denuncia a "el cavesia de este pueblo Miguel Chaves en reunion de trese indigenas mas an marchado para el rio llaqui, no se sabe con que objeto pero se supone de rebolusionar a los demas que se llaman gandaristas". ${ }^{99}$ Asimismo se denuncia a Ramón Tánori en marzo de 1857 por no atender a las órdenes del gobierno de dirigir una partida contra el enemigo apache y en cambio unirse a los "alzados de tepupa". ${ }^{60}$ De esta forma tenemos que mientras los grupos ópatas hasta este momento habían tenido una actitud estable con las autoridades estatales manteniendo el orden y la tranquilidad, a partir de 1855 comienzan reportes de desobediencia de sus autoridades. En este sentido, ¿qué motivó las acciones de estos grupos ópatas?

${ }^{56}$ Revilla, Utopías liberales..., p. 105.

${ }^{57}$ Norma de León, El conflicto apache en Sonora bajo el gobierno del general Ignacio Pesqueira 1867-1872, Hermosillo, El Colegio de Sonora, 2012, p. 66.

${ }^{58}$ León, El conflicto apache..., p. 72.

${ }^{59}$ AGES, FE, RP, t. 19, exp. 2, doc. 013790: Pueblo de Onavas, julio 12 de 1857.

${ }^{60}$ AGES, FE, RP, t. 307: Ures, marzo 6 de 1857. 
Las incursiones de cabecillas rebeldes ópatas y pimas, que anteriormente habían sido relegados por la documentación tan abundante de lo acontecido en el Yaqui, fueron cada vez más frecuentes; tal es el caso de un grupo de indios de Ónavas y Tónichi que se levantaron en contra de Pesqueira exigiendo el regreso de Manuel María Gándara; dichas gavillas eran constantemente relacionadas con uno de los hermanos menores de Manuel Gándara, Jesús Gándara, de quien se consideraba que estimulaba activamente el descontento contra Pesqueira. ${ }^{61}$

El proceder de los ópatas se realizaba a través de incursiones sorpresa, o una "guerra de guerrillas". ${ }^{62}$ Por lo general las incursiones se orientaban a la búsqueda de armas, robo de semovientes, alimentos y bebidas; así pues, trastocaban el orden a través de robos o saqueos a las casas principales. ${ }^{63}$ En la documentación se hacía mención mayormente de los gavilleros Tánori, refiriéndose a Juan Tánori, cabecilla principal, y la unión a éstos de los hermanos Pedro y Pablo Leyva. ${ }^{64}$ El primero firma la documentación como capitán general de ópatas, aceptado por éstos pero sin el reconocimiento de las autoridades pesqueiristas. Juan y Refugio Tánori son continuamente reportados como cabecillas de gavillas de indígenas rebeldes, a quienes continuamente auxilian las gavillas de Pedro y Pablo Leyva.

Sin embargo, no es hasta junio de 1859 cuando las gavillas de Tánori causan revuelo entre las autoridades estatales recorriendo las zonas de Suaqui, Comuripa, Ónavas, Suaqui, Soyopa y Movas, y manteniendo "gavillas separadas [donde] tienen interceptado el camino de Hermosillo y recorren las intermediaciones de la capital". ${ }^{65}$ Se señalaba como cabecilla principal a Juan Tánori, seguido de Refugio Tánori, Pedro Leyva y Desiderio Maza; se estipulaba que el número de sublevados ascendía a 400 hombres entre ópatas, pimas, yaquis y gente blanca que seguían a Tánori "causando el mal de haber limpiado de bestias y armas [...] y bastimento". ${ }^{66}$

Dichas acciones estaban directamente relacionadas con los planes de colonización de territorio yaqui y mayo que Pesqueira había ejecutado

${ }^{61}$ Rodolfo Acuña, Caudillo sonorense. Ignacio Pesqueira y su tiempo, México, Era, 1981 (Colección Problemas de México), p. 57.

${ }^{62}$ Armando Quijada y Juan Antonio Ruibal, Historia general de Sonora, t. III, p. 165.

${ }^{63}$ AGES, FE, t. 288: juzgado y ayuntamientos, Ures 15 de septiembre de 1857.

${ }^{64}$ AGES, FE, t. 285, Hermosillo, noviembre 1 de 1857.

${ }^{65}$ AGES, FE, RP, t. 330: Libro de borradores en minuta, Ures, junio 2 de 1859.

${ }^{66}$ AGES, FE, RP, t. 341: Correspondencia habida en la prefectura del Altar, julio de 1859, Altar, julio 6 de 1859. 
especialmente el 4 de agosto de 1859 con el establecimiento de la Colonia Pesqueira, misma que contaría con 10500 hectáreas, para fundo legal y ejidos, y cuya área de cultivo sería vendida a colonos. ${ }^{67}$ Asimismo, la publicación de decretos mediante los cuales "se proponía el establecimiento de una compañía explotadora de los terrenos del Yaqui, en la que exponía su deseo de construir tomas de agua para riego" ${ }^{68}$ para deslindar terrenos en dicho valle.

Los puntos de llegada de los gavilleros Tánori comenzaban en los pueblos de Comuripa y Movas, según los reportes, y su avance siguió hasta Tepupa desde distintos puntos. La acción de las gavillas se encontraba enmarcada en el pronunciamiento del Plan de Tepupa que otorgaba reconocimiento al Plan de Tacubaya; ante lo ocurrido, Domingo Jiménez, capitán del pueblo de Ónavas, explica la influencia que tiene Juan Tánori donde dice "que da unas habladas en contra del Gob. y en fabor [sic] de los de su partido [...] que este es de muy malas intenciones y nunca dejara de trabajar en fabor [sic] de los malbados, ciendo este a pesar de ser tan malo uno de los indios que hai de mas influjo entre estos [...] que mientras se consienta esta clace [sic] de sujetos en los pueblos nunca estaremos en pas [sic]". ${ }^{69}$ Lo anterior puede demostrar que los liderazgos se forjan nuevamente después del deceso de Luis Tánori, cuando Juan Tánori es reconocido por las gavillas de indios que son sus seguidores, y quienes manifiestan continuamente sus alianzas con Gándara a través de su hermano Jesús Gándara.

Posiblemente, esta fue una forma para restablecer un gobierno indígena legítimo después de la muerte de Luis Tánori y ser afirmado con el ascenso de Gándara nuevamente al poder estatal. Los líderes ópatas buscaban a través de las insurrecciones la representación política del cargo de capitán general que habían perdido con la muerte de Luis Tánori y que, consideraban, podría lograrse a través del pacto con Gándara; sin embargo, una vez establecido Pesqueira en el poder, se omitía la negociación. Las incursiones de 1859 se acrecentaban y es por eso que "Pesqueira regresa de su intervención en Mazatlán, Sinaloa, a razón de la sublevación de Tánori, ${ }^{70}$ quien acompañado de su hermano Refugio Tánori contaba con gavillas numerosas, que se engrosaron con la integración de la banda de Pedro y Pablo Leyva”. ${ }^{71}$

\footnotetext{
${ }^{67}$ Revilla, Utopías liberales..., p. 95-96.

${ }^{68}$ Revilla, Utopías liberales..., p. 96.

${ }^{69}$ AGES, FE, RP, t. 348: Ramo Militar en el estado, abril de 1860. Onavas, abril 6 de 1860.

${ }^{70}$ AGES, FE, RP, t. 344: Mazatlán, abril 26 de 1859.

${ }^{71}$ AGES, FE, RP, t. 344: Prefectura del río Yaqui. Cócorit, abril 4 de 1859.
} 
Las gavillas de los Tánori y Leyva estaban enmarcadas en el Plan de Tepupa, que hacía alusión al Plan de Tacubaya y al reconocimiento de Félix Zuloaga como presidente de México en contraposición al grupo liberal de Benito Juárez. ${ }^{72}$ El Plan de Tepupa tenía como primera enmienda la eliminación del general Ignacio Pesqueira como gobernador del estado considerando "que la permanencia en el gobierno de D. Ignacio Pesqueira está causando la ruina de todos los habitantes del estado porque se gasta todas las rentas del erario"; "que todas las contribuciones directas y voluntarias que ha impuesto á los habitantes del mismo Estado no han sido para perseguir a los apaches"; y finalmente, que en "lugar de perseguir á los apaches se ha salido fuera del Estado a revolucionar", hemos venido a decretar:

Art. 1. Que nos adherimos al Plan de Tacubaya proclamado por D. Félix Zuloaga.

Art. 2. Desconocemos á la persona del gobernador D. Ignacio Pesqueira con todas las autoridades y todas las leyes y decretos que ha expedido en todo el tiempo que ha sido gobernador y nos sujetamos a todas las leyes y decretos espedidos por D. Manuel María Gándara en el tiempo que fue gobernador de Sonora.

Art. 3. Proclamamos para gobernador del Estado al benemerito general D. Manuel María Gándara quien desde luego se posesionará del gobierno y nombrará nuevas autoridades.

Art. 4. [...] y protestamos no abandonar las armas de la mano hasta ver concluidos nuestos deseos espresados en los artículos anteriores. ${ }^{73}$

Hay varios puntos clave en dichos postulados; entre ellos, desconocer a Pesqueira, sus autoridades y los decretos expedidos. Posteriormente, reconocer a Manuel María Gándara como gobernador del estado con los decretos expedidos por él durante su gobierno, así como por el nombramiento de nuevas autoridades. Los postulados anteriores dan margen a cuestionarse qué autoridades, leyes o decretos fueron expedidos por Pesqueira que afectaban los intereses de Tánori y sus seguidores. Para el 14 de julio de 1859, tan sólo dos días antes del pronunciamiento de Juan Tánori, Pesqueira envió una circular al gobierno de la república enumerando las medidas que se iban a tomar contra los "latrofacciosos"; "a los rebeldes de julio de 1856 y noviembre de 1857 que dominan el ánimo de los habitantes de aquellos pueblos, haciendas y ranchos en donde los criminales se abrigan

${ }^{72}$ Almada, Diccionario de historia..., p. 540.

${ }^{73}$ La Estrella de Occidente, n. 6, viernes 15 julio de 1859, p. 3. 
y mantienen ejerciendo el pillage [sic]". Conociendo la falta de efectividad del gobierno para su castigo, Pesqueira estipulaba las siguientes resoluciones para los criminales:

[...] Extraer de los pueblos, haciendas y ranchos a cuantos individuos sean convictos de haber levantado las armas para engrosar gavillas latrofacciosas.

2a. Perseguir sin tregua a los sublevados que actualmente figuran como cabecillas y que por la gravedad de sus crímenes merecen la última pena.

[...] los criminales que sean aprehendidos y se encuentren en el caso de la primera o segunda prevención, se remitirán á esta capital con las seguridades convenientes para que sean calificados y juzgados conforme á la ley de conspiradores. $^{74}$

Además de lo anterior, también declaraba mayor control sobre los hacendados y sobre sus trabajadores; por tanto dispondría celadores bajo la responsabilidad de los jueces locales que rectificarían con una lista a las personas avecindadas, así como una lista nominal de las personas que compondrían la servidumbre, sus antecedentes, actividades e inclinaciones. En este sentido, ¿̇fue el Plan de Tepupa una respuesta a lo informado por Pesqueira o parte de una enmienda nacional? Posiblemente fueron ambas. La amenaza directa de Pesqueira hacia Tánori y Leyva e inclusive a cabecillas ópatas como Miguel Chávez por su participación en las gavillas de noviembre de 1857 era evidente; asimismo, las sublevaciones yaquis de julio de 1856 encabezadas principalmente por Mateo Marquín y seguidas por indios yaquis reunidos al mando de Jesús Gándara. El castigo era ejemplar: la pena última, la acusación de conspiradores y la aprehensión de sus familias.

En este sentido, Juan Tánori encabezando a otros cabecillas ópatas como Refugio Tánori, Pedro Leyva, Desiderio Maza y Miguel Chávez participó del pronunciamiento gandarista con la finalidad de contraponerse de primera mano a la autoridad de Pesqueira y apoyando a Gándara, un personaje conocido en la sociedad indígena por establecer pactos duraderos a través de los capitanes generales, cuyo reconocimiento no era otorgado por las autoridades estatales en ese momento. Dicho cargo era de una importancia elemental, posiblemente era la única fuente de acción que podía contrariar el avance de las medidas radicales de Pesqueira, ante la inminente fragmentación política de las etnias y la colonización de su territorio.

${ }^{74}$ AGES, FE, RP, t. 345: Circulares, Gobierno del Estado, Ures, julio 14 de 1859. 


\section{Consideraciones finales}

Las insurrecciones de indios en Sonora durante 1855 a 1859 pueden ser abordadas desde las distintas perspectivas que proveen los estudios subalternos. En primera instancia, como antecedente de las insurrecciones indígenas en contra del poder estatal, existieron intentos previos de negociación mediados por el cargo de capitán general, especialmente el ejercido por Mateo Marquín y Luis Tánori. Sin embargo, a la entrada de Pesqueira a la gubernatura, se rompió el pacto establecido por los sucesivos gobiernos de Gándara con autoridades indígenas. Desaparecen cargos con la finalidad de fragmentar la unidad de los grupos indígenas; se estipulan decretos en su contra con el objetivo de seguir y castigar a los sublevados al orden de forma ejemplar.

En este sentido, las legislaciones y decretos especiales para el gobierno de los indígenas establecidos en 1853 y 1857 funcionaron como un instrumento de subalternización por parte del estado y dieron margen de interpretación acerca de las facultades que cada cargo tenía, propiciando la fragmentación del poder de los grupos indígenas. La estrategia utilizada fue dar predominancia a ciertas personas con autoridad dentro de la etnia como alcaldes y gobernadores, para crear conflictos entre ellos.

Entre los años de 1857 y 1859 las insurrecciones indígenas fueron una constante en los reportes de autoridades estatales y vecinos, ¿qué incentivó la unión de grupos ópatas y yaquis al mando de los hermanos Leyva y los Tánori? Una vez establecido en el gobierno, Ignacio Pesqueira se convirtió en un enemigo en común de grupos descontentos. En primera instancia, Pesqueira representaba al liberalismo radical que no convivía con las formas anteriores de hacer política a través de pactos o negociaciones; asimismo, instaba a la desaparición de cargos indígenas que tenían legitimidad y autoridad dentro de su grupo, quienes se distinguían por la autonomía en su actuar y la posibilidad de incitar a una rebelión si convenía a sus intereses.

En aquellos años, estos líderes de gavillas - Tánori y Leyva- se relacionaron con la causa gandarista después de que sus medios de negociación fueron inexistentes, emplearon enmiendas locales y nacionales para provocar un escenario político en donde pudieran ser representados. En este sentido, se pronunciaron con el Plan de Tepupa, el cual se adhería al Plan de Tacubaya reconociendo a Félix Zuloaga como presidente y a Gándara como gobernador en contraposición de Ignacio Pesqueira. Este último, no sólo perdió los lazos con las autoridades indígenas sino que las condenó 
estipulando prevenciones y castigos ejemplares a aquellos que hubieran participado en los conflictos relacionados con Gándara, propiciando entonces mayor énfasis en la contraposición de líderes como Juan Tánori al gobierno de Pesqueira.

La anexión al Plan de Tacubaya posiblemente no estaba relacionada con el sistema político que se eligiera a nivel nacional ni la figura representante; pero sí existía una acción social dirigida al apoyo de un personaje como Gándara, mismo que había empoderado a los capitanes generales durante su estancia en el poder por años y cuya cultura política, radicaba en negociar y pactar con las autoridades indígenas. Posiblemente fue el mecanismo más idóneo para conseguir nuevamente una mediación política que diera voz a su cultura, sus demandas y su representación en un contexto que parecía orientado a desaparecerlas.

\section{Fuentes}

Siglas

AGES, FE Archivo General del Estado de Sonora, Hermosillo, México, Fondo Ejecutivo.

AGES, RP Archivo General del Estado de Sonora, Hermosillo, México, Ramo Prefecturas.

Bibliografía

Acuña, Rodolfo, Caudillo sonorense. Ignacio Pesqueira y su tiempo, México, Era, 1981 (Colección Problemas de México).

Almada Bay, Ignacio, Breve historia de Sonora, México, Fondo de Cultura Económica/El Colegio de México, 2000.

Almada, Francisco R., Diccionario de historia, geografía y biografía sonorense, Hermosillo, Gobierno del Estado de Sonora/Instituto Sonorense de Cultura, 1990, p. 925-945.

Cramaussel, Chantal, "Reseña sobre Esperanza Donjuan Espinoza, Raquel Padilla Ramos, Dora Elvia Enríquez Licón, Zulema Trejo Contreras, Religión, nación y territorio en los imaginarios sociales indígenas en Sonora, 1767-1940", Relaciones, n. 142 , primavera 2015 , p. 320-325. 
GARCía RIVERA, Lucía, Liderazgos, pactos e insurrecciones. Líderes indígenas y el poder estatal, 1843-1859, tesis de doctorado en Ciencias Sociales, Hermosillo, El Colegio de Sonora, Estudios Históricos de Región y Frontera, 2016.

García Rivera, Lucía, y Zulema Trejo, "Entre el poder y la autoridad: Mateo Marquín, capitán general de yaquis y mayos de 1843 a 1857”, Relaciones. Estudios de Historia y Sociedad, v. 39, n. 153, enero 2018, p. 227-259.

GuHA, Ranahit, Las voces de la historia y otros estudios subalternos, prólogo de Josep Fontana, traducción castellana de Gloria Cano, Barcelona, Crítica, 2002.

Hernández Silva, Héctor Cuauhtémoc, Insurgencia y autonomía. Historia de los pueblos yaquis: 1821-1910, México, Centro de Investigaciones y Estudios Superiores en Antropología Social/Instituto Nacional Indigenista, 1996.

Hu DeHart, Evelyn, Yaqui Resistance and Survival: The Struggle for Land and Autonomy, 1821-1910, Madison (Wisconsin), The University of Wisconsin Press, 1984.

Jong, Ingrid de, "Armado y desarmado de una confederación: el liderazgo de Calfucurá en el periodo de organización nacional”, Quinto Sol. Revista de Historia Regional, n. 13, 2009, p. 11-45.

LEÓn, Norma de, El conflicto apache en Sonora bajo el gobierno del general Ignacio Pesqueira, 1867-1872, Hermosillo, El Colegio de Sonora/Colegio de Bachilleres de Sonora, 2012.

LIRA, Andrés, y Anne Staples, "Del desastre a la reconstrucción republicana, 18481876”, en Nueva historia general de México, México, El Colegio de México, 2010.

Medina Bustos, José Marcos, "Cargos militares indígenas en la transición del antiguo régimen al liberalismo”, Revista de Ciencias Sociales, Universidad de Quilmes, Buenos Aires, Argentina, año 3, n. 20, 2011, p. 29-48.

Modonesi, Massimo, Subalternidad, en línea, México, Universidad Nacional Autónoma de México, Instituto de Investigaciones Sociales, 2012 (Conceptos y Fenómenos Fundamentales de Nuestro Tiempo). Disponible en: http://conceptos.sociales.unam.mx/conceptos_final/497trabajo.pdf

PADIlla, Raquel, y Zulema Trejo, “Los ocho pueblos como concepto”, en Conflicto y armonía, etnias y poder civil, militar y religioso en Sonora, México, Instituto Nacional de Antropología e Historia, 2009, p. 195-212.

QuiJadA, Armando, y Juan Antonio Ruibal, Historia general de Sonora, 2a. ed., 6 v., Hermosillo, Instituto Sonorense de Cultura, 1997, v. III.

RADDING, Cynthia, Entre el desierto y la sierra. Las naciones o'odham y tegüima en Sonora, 1530-1840, México, Centro de Investigaciones y Estudios Superiores en Antropología Social/Instituto Nacional Indigenista, 1995.

Ramírez Zavala, Ana Luz, "De todo se han aprovechado esos hombres políticos y revolucionarios". Los yaquis durante el proceso de formación del Estado posrevo- 
lucionario: negociación y cambio cultural, 1920-1940, tesis de doctorado en Historia, México, El Colegio de México, 2014. , "Cambios en la estructura militar yaqui durante el siglo XIX", Primer Congreso Internacional de los Pueblos Indígenas de América Latina, Siglos XIX-XXI, Oaxaca, México, octubre de 2013.

Revilla Celaya, Iván, Utopías liberales: proyectos de colonización y rebeliones indígenas en los valles del Yaqui y del Mayo, 1853-1867, Hermosillo, El Colegio de Sonora, [2014].

SAlomón TARQuini, Claudia, "Procesos de subalternización de la población indígena en Argentina: los ranqueles en La Pampa, 1870-1970”, Revista de Indias, v. 71, n. 252, 2011, p. 545-570.

SPICER, Edward, Los yaquis. Historia de una cultura, México, Universidad Nacional Autónoma de México, Instituto de Investigaciones Históricas, 1994.

Trejo, Zulema, "Leyes especiales para el gobierno de los pueblos indígenas de Sonora, 1831-1853”, Fronteras de la Historia, Instituto Colombiano de Antropología e Historia, Bogotá, Colombia, v. 18, n. 2, julio-diciembre 2013, p. 105-131.

Zermeño Padilla, Guillermo, "Condición de subalternidad, condición postmoderna y saber histórico. ¿Hacia una nueva forma de escritura en la historia?, Historia y Grafía, México, n. 12, 1999, p. 11-47. 